Infusiostherapie 1991;18:209

\title{
Impressum, Vol. 18, No. 5, 1991
}

\section{Herausgeber}

\section{S. Karger}

Verlag für Medizin und Naturwissenschaften GmbH, Postfach 1724, D-8034 Germering

Presserechtlich verantwortlich: Walter Kunz, Gesellschafter

Offizielles Organ

der Deutschen Gesellschaft für Transfusionsmedizin

und Immunhämatologie

Gründungsherausgeber

H. Reissigl, w. Hofrat, Innsbruck

Schriftleitung

A. Grünert, Ulm V. Kretschmer, Marburg W. Stangel, Hannover K. Widhalm, Wien G.

Wolfram, München

Wissenschaftlicher Beirat

M. Adolph, Augsburg

F.W. Ahnefeld, Ulm

K.H. Bäßler, Mainz

W. Behrendt, Aachen

H. Bergmann, Linz

C. Bode, Köln

H. Böhles, Frankfurt

P. Deetjen, Innsbruck

W. Dick, Mainz

R. Dölp, Fulda

H. von Domarus, Lübeck

W. Druml, Wien

J. Eckart, Augsburg

P. Ferenci, Wien

H. Förster, Frankfurt

R. Glaser von Roman, Düsseldorf

A. Grünert, Ulm

J.M. Hackl, Innsbruck

W. Haider, Wien

M. Halmágyi, Mainz W. Hartig, Leipzig O. Heidenreich, Aachen U. Henneberg, Berlin

E. Holm, Mannheim

G. Kleinberger, Steyr

K.F. Kopp, München

V. Kretschmer, Marburg

J. Kult, Bad Mergentheim 


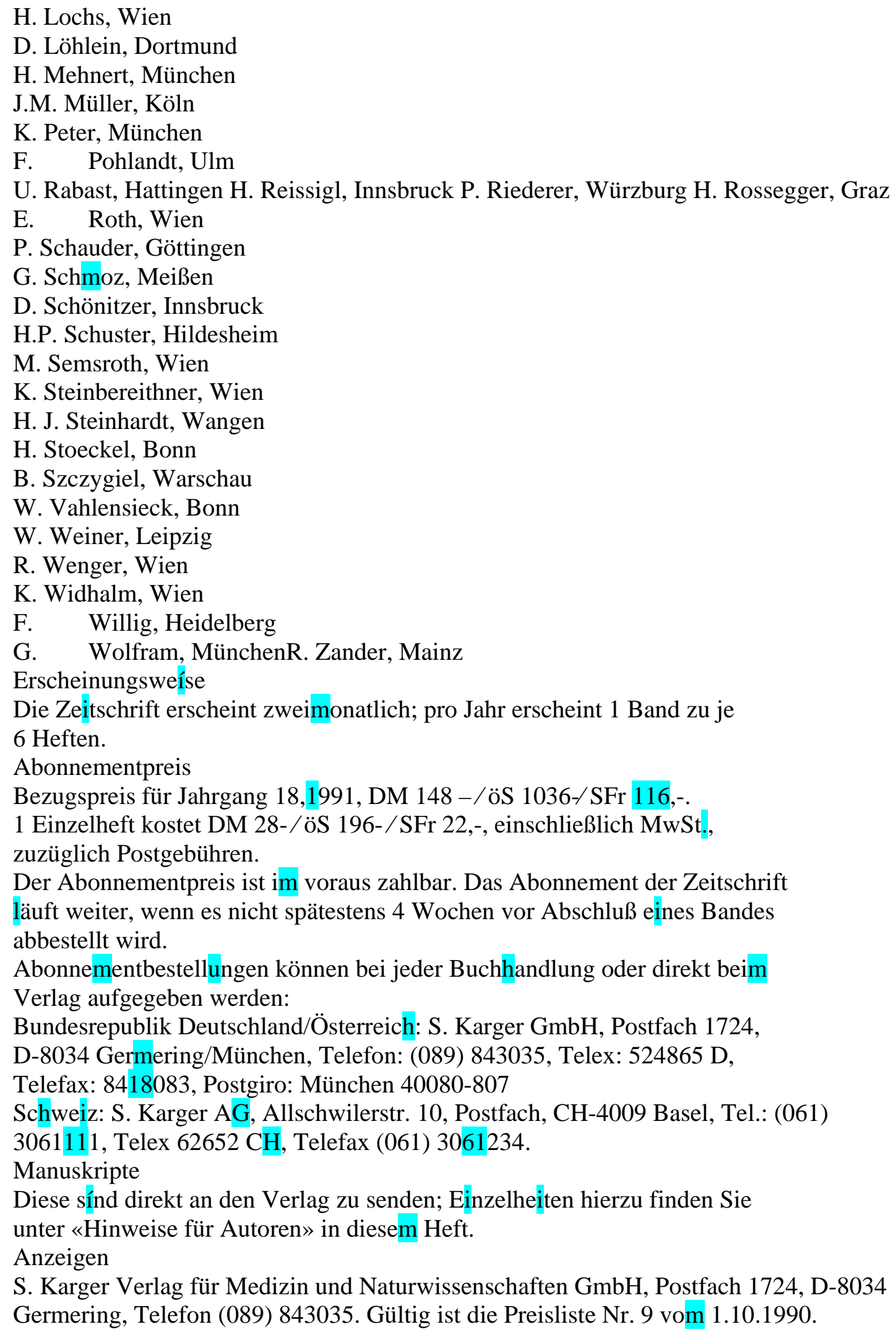


Für den Inhalt außerhalb des redaktíonellen Teiles (insbesondere Anzeigen, Industrieinformationen, Pressezitate und Kongreßinformationen usw.) über-nehmen Schriftleitung, Beirat und Verlag keinc Gewähr.

Eine Markenbezeichnung kann warenzeichenrechtlich geschützt sein. auch wenn bei ihrer Verwendung in dieser Zeitschrift das Zeichen (c) oder ein anderer Hin-weis auf etwa bestehende Schutzrechte fehlen sollte. Für Satzfehler, insbesondere bei Dosierungsangaben, wird keine Gewähr übernommen.

Alle Rechte. insbesondere das Recht der Vervielfältigung und Mikrokopio sowie der Übersetzung. vorbehalten. Nachdruck, auch auszugsweise, nur mit Geneh-migung des Verlages. Fotokopien dUrfen nur für den persönlichen Gebrauch als Einzelkopien hergestellt werden. Jede im Bereich eines gewerblichen Unterneh-mens zulässig hergestellte oder benutzte Kopie dient gewerblichen Zwecken gem. § 54(2) UrhG und verpflichtet zur Gebührenzahlung an die Verwertungs-gesellschaft WORT, Abt. VG Wissenschaft, Goethestr. 49, D-8000 München 2. (C) Copyright 1991 by S. Karger, Verlag für Medizin und Naturwissenschaften GmbH, Postfach 1724, D-8034 Germering (BRD)

Vcrlagsleitung: Manfred Just Redaktionsassistenz: Anne Schieber Anzeigenverkauf: Marlene Scholz Anzeigenverwaltung: Eva Lindenau Herstellung: Horst H. Bruch Vertrieb: Gabriela Taube

Satz und Druck: Walter Biering GmbH, Grafischer Betrieb Freisinger Landstraße 21 , D-8000 München 45 (BRD)

KARGER 